\title{
Investigation of PMU performance under TVE criterion
}

\author{
Yang, GuangYa; Martin, K. E.; Østergaard, Jacob
}

Published in:

The 5. International CRIS conference on Critical Infrastructures

Link to article, DOI:

10.1109/CRIS.2010.5617541

Publication date:

2010

Document Version

Publisher's PDF, also known as Version of record

Link back to DTU Orbit

Citation (APA):

Yang, G., Martin, K. E., \& Østergaard, J. (2010). Investigation of PMU performance under TVE criterion. In The 5. International CRIS conference on Critical Infrastructures https://doi.org/10.1109/CRIS.2010.5617541

\section{General rights}

Copyright and moral rights for the publications made accessible in the public portal are retained by the authors and/or other copyright owners and it is a condition of accessing publications that users recognise and abide by the legal requirements associated with these rights.

- Users may download and print one copy of any publication from the public portal for the purpose of private study or research.

- You may not further distribute the material or use it for any profit-making activity or commercial gain

- You may freely distribute the URL identifying the publication in the public portal

If you believe that this document breaches copyright please contact us providing details, and we will remove access to the work immediately and investigate your claim. 


\title{
Investigation of PMU Performance under TVE Criterion
}

\author{
G. Y. Yang, Member, IEEE, K. E. Martin, Fellow, IEEE, J. Østergaard, Senior member, IEEE
}

\begin{abstract}
Phasor measurement unit (PMU) is an emerging measurement technology for power grids which enables the synchronised high speed measurement with precise time stamps for accurate system comparison over a wide geographic area. PMU measurement quality is the key issue in application purposes. To evaluate the measurement quality, the concepts of total vector error (TVE) and benchmark tests, including the magnitude, phase and frequency step tests, are proposed in the C37.118 standard. It also includes requirements for test results. This paper reports the results of tests performed on several PMUs. These tests include both steady state and dynamic conditions conforming to the new requirements under development by the IEEE for the updated C37.118 standard. In addition to validating the new IEEE requirements with actual PMU measurements, the results evaluated by TVE are discussed and with errors analyzed based on phasor magnitude and angle.
\end{abstract}

Index Terms-Phasor measurement unit, synchrophasor, PMU tests, total vector error

\section{INTRODUCTION}

$\mathrm{P}$ HASOR measurement unit (PMU) is an emerging measurement technology for power grids which enables the synchronised high speed measurement with precise time stamps for accurate system comparison over a wide geographic area. Many utilities in the world have installed PMUs in their main substations and power plants with high speed communication channels to send the data to a control center. The basic measurement quantities from a PMU are voltage and current phasors. Besides this, a PMU can also provide secondary quantities such as power, frequency, and frequency change rate. The IEEE standard C37.118-2005 defines synchronised phasor, time synchronisation, reporting format, and measurement quality test criterion to facilitate the utilisation of this technology $\{, 2006 \# 1\}$. This emerging technology has been recognised for its high potential in improving power system operation, management, and control.

Basic measurement provided by PMU includes positive sequence components of voltage, current. With sufficient sample rate and accurate synchronisation with UTC time, PMU provides usable positive sequence phasor values under most system conditions. Also, secondary electrical quantities, such as power, frequency and frequency change rate, can be derived from phasor measurement. Commonly adopted phasor

G. Y. Yang and J. Østergaard are with Centre for Electric Technology, Technical University of Denmark, Kgs. Lyngby DK-2800 (e-mail: \{gyy, joe\}@elektro.dtu.dk).

K. E. Martin is with Electric Power Group and Quanta Technology, USA. (e-mail: ken.martin8421@yahoo.com). estimation approach is the discrete Fourier transform (DFT).

PMU measurement quality is the key issue in application purposes. In the standard $\mathrm{C} 37.118$, the requirement for compliance is categorised into Level 0 and Level 1 considering different ranges of influence quantities of the signal under steady-state conditions. The requirement for the measurement quality may also consider the factors such as application purposes, reporting rate, etc. To evaluate the measurement quality, the concepts of total vector error (TVE) and benchmark tests, including the step tests on magnitude, phase and frequency step tests, are proposed in the C37.118 standard. TVE is defined by the root squared difference between the mathematically defined phasor $X$ and estimated phasor $X(n)$,

$$
\varepsilon=\frac{|X(n)-X|}{|X|} \times 100 \%
$$

Compliance with the standard requires a measurement difference within $1 \%$ under a variety of conditions. For PMU tests, efforts have been given to develop the necessary test plans for PMU performance evaluation $\{$ K. E. Martin, 2007 \#4; K. E. Martin, $2006 \# 13$. The test plans vary the amplitude, frequency, and phase angle of signal quantities to cover the steady-state and dynamic situations in the real system operation. From this principle, quite a few researchers started to study the characterization of PMU measurement under dynamic conditions and the possibility of error compensation .

This paper reports the initial results of tests performed on two PMUs from different manufacturers. These tests include both steady state and dynamic conditions conforming to the new requirements under development by the IEEE for the updated C37.118 standard. In addition to validating the new IEEE requirements with actual PMU measurements, the results evaluated by TVE are compared with errors analyzed based on phasor magnitude and angle.

\section{THEORETICAL PHASOR MODELS OF TESTS}

The PMU test plans need to consider the accuracy of the basic quantities including amplitude, frequency, and phase angle, measured over a range of signal situations. The test plans developed in this work are a continuous effort of the authors' previous work. To compare the TVE conforming to the standard, the theoretical phasors are formulated for different tests for comparison. 


\section{1) Generalized phasor function}

Given the instantaneous sinusoid function at nominal frequency $\omega_{0}$ with amplitude and phase angle varying:

$$
\mathrm{X}(\mathrm{t})=\mathrm{X}_{\mathrm{m}}[\mathrm{g}(\mathrm{t})] \cdot \cos \left[\omega_{0} \mathrm{t}+\mathrm{y}(\mathrm{t})\right]
$$

where $g(t)$ is the signal amplitude function, $y(t)$ is a phase angle function. In the test plans, $g(t)$ and $y(t)$ can be varied in different ways to represent the real system conditions. According to Eq. (2), the corresponding theoretical phasor value is:

$$
\mathrm{X}(\mathrm{nT})=\left[\mathrm{X}_{\mathrm{m}} / \sqrt{2}\right][\mathrm{g}(\mathrm{nT})] \angle[\mathrm{y}(\mathrm{nT})]
$$

where $n T$ is the reporting instant ( $\mathrm{n}$ is an integer and $\mathrm{T}=1 / \mathrm{Fs}$ where $\mathrm{Fs}$ is the phasor reporting rate). The phasor values reported by the PMU should be an estimation of this value for each given instant of time.

2) Steady-state tests

Steady state tests are characterized by the parameters of the measured phasor being constant during the test. To test at different amplitudes, angles, and frequencies, the signal parameter is changed and then held constant for a period of time (Dwell) so the PMU can settle from any transients created by the change and create a steady state measurement. All measurements that do not require a continuous change are held at a specific value for $5-10 \mathrm{sec}$ to allow making the measurement evaluation over an interval rather than at a single point. This allows finding average and maximum values for a better evaluation of the PMU. The tests studied in this work include the scan of amplitude, frequency and phase angle.

\section{a) Signal magnitude}

For the amplitude scan, the magnitude of the signals is incremented from $0.1 \mathrm{pu}$ to $1.2 \mathrm{pu}$ and $0.1 \mathrm{pu}$ to $2 \mathrm{pu}$ for voltage and current, respectively. As can be seen from Fig. 1, at each value, the amplitude of the test signal keep constant for a time period and then change to the new value.

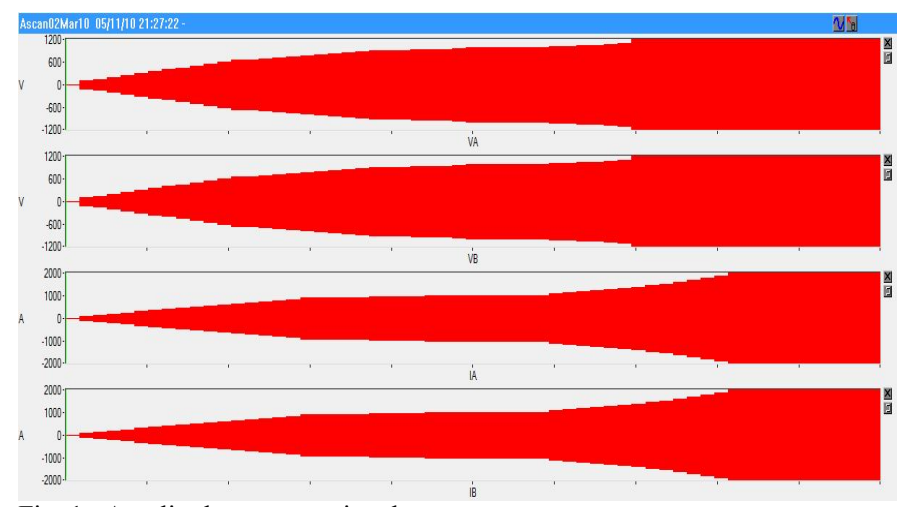

Fig. 1. Amplitude scan test signals

Since the phase angle and frequency are keeping constant through the whole test, for the theoretical phasor value, there should be no angle shift throughout the test for each phase. The measured synchrophasor shall be having the value,

$$
\mathrm{X}(\mathrm{nT})=\left[\mathrm{X}_{\mathrm{m}} / \sqrt{ } 2\right][\mathrm{g}(\mathrm{nT})] \angle \theta
$$

where the $\theta$ is an arbitrary phase angle.

\section{b) Signal phase angle}

For phase scan, the test varies the signal phase over a full circle. The test signals are exactly the same for voltage and current except for the scaling and range.

$$
\mathrm{X}(\mathrm{nT})=\left[\mathrm{X}_{\mathrm{m}} / \sqrt{2}\right] \angle[\mathrm{y}(\mathrm{nT})]
$$

where the $X_{m} / \sqrt{2}$ is the constant amplitude.

\section{3) Dynamic tests}

The dynamic tests refer to the modulation test and frequency ramping test.

\section{a) Modulation tests}

The modulation tests include the tests on amplitude, frequency, and the phase angle. The expression of a generalized modulation signal is

$$
\begin{aligned}
& X_{a}=X_{m}\left[1+k_{x} \cos \left(\omega_{x} t\right)\right] \cdot \cos \left[\omega_{0} t+k_{a} \cos \left(\omega_{a} t-\pi\right)+\theta_{a}\right] \\
& X_{b}=X_{m}\left[1+k_{x} \cos \left(\omega_{x} t\right)\right] \cdot \cos \left[\omega_{0} t-2 \pi / 3+k_{a} \cos \left(\omega_{a} t-\pi\right)+\theta_{a}\right] \\
& X_{c}=X_{m}\left[1+k_{x} \cos \left(\omega_{x} t\right)\right] \cdot \cos \left[\omega_{0} t+2 \pi / 3+k_{a} \cos \left(\omega_{a} t-\pi\right)+\theta_{a}\right]
\end{aligned}
$$

where $X_{m}$ is the amplitude of the input signal, $\omega_{0}$ is the nominal power system frequency, $\omega_{\mathrm{a}}$ and $\omega_{\mathrm{x}}$ are the modulation frequency for amplitude and phase angle, $\mathrm{k}_{\mathrm{x}}$ is the amplitude modulation factor, $\mathrm{k}_{\mathrm{a}}$ is the phase angle modulation factor and $\theta_{\mathrm{a}}$ is an arbitrary phase angle.

The positive sequence signal corresponding to the above three phase input is given by

$$
\mathrm{X}_{1}=\mathrm{X}_{\mathrm{m}}\left[1+\mathrm{k}_{\mathrm{x}} \cos \left(\omega_{\mathrm{a}} \mathrm{t}\right)\right] \cdot \cos \left[\omega_{0} \mathrm{t}+\mathrm{k}_{\mathrm{a}} \cos \left(\omega_{\mathrm{x}} \mathrm{t}-\pi\right)+\theta_{\mathrm{a}}\right]
$$

At reporting times $\mathrm{nT}$, a PMU shall produce the positive sequence synchrophasor given by

$$
\mathrm{X}(\mathrm{nT})=\left\{\mathrm{X}_{\mathrm{m}} / \sqrt{2}\right\}\left[1+\mathrm{k}_{\mathrm{x}} \cos \left(\omega_{\mathrm{a}} \mathrm{nT}\right)\right] \angle\left\{\mathrm{k}_{\mathrm{a}} \cos \left(\omega_{\mathrm{x}} \mathrm{nT}-\pi\right)+\theta_{\mathrm{a}}\right\}
$$

A phase is the same and $B$ and $C$ phases will be the same except rotated by $\pm 2 \pi / 3$ to correspond with the input signals.

b) Frequency ramping test

Mathematically the input signals may be represented by

$$
\begin{aligned}
& X_{a}=X_{m} \cos \left[\omega_{0} t+\pi(d f / d t) t^{2}\right] \\
& X_{b}=X_{m} \cos \left[\omega_{0} t-2 \pi / 3+\pi(d f / d t) t^{2}\right] \\
& X_{c}=X_{m} \cos \left[\omega_{0} t+2 \pi / 3+\pi(d f / d t) t^{2}\right]
\end{aligned}
$$

where $X_{m}$ is the amplitude of the input signal, $\omega_{0}$ is the nominal power system frequency, and (df/dt) is the frequency ramping rate (fixed value in this equation).

The positive sequence signal corresponding to the above three phase inputs is given by:

$$
\mathrm{X}_{1}=\mathrm{X}_{\mathrm{m}} \cos \left[\omega_{0} \mathrm{t}+\pi(\mathrm{df} / \mathrm{dt}) \mathrm{t}^{2}\right]
$$

At reporting times $\mathrm{nT}$ the PMU shall produce a synchrophasor measurement for A phase and positive sequence of:

$$
X(n T)=\left[X_{m} / \sqrt{ } 2\right] \angle\left[\pi(d f / d t)(n T)^{2}\right]
$$

B \& C phase measurements will be the same except rotated by $\pm 2 \pi / 3$ to correspond with the input signals. 


\section{4) Harmonic distortion}

Harmonics should be completely rejected by the phasor measurement process, and should not appear in the measurement. The harmonics are added one at a time to the signal and the measurement is checked for errors. The harmonics formulas are as shown below:

$$
\begin{aligned}
& \mathrm{X}_{\mathrm{a}}=\mathrm{X}_{\mathrm{m}}\left[\mathrm{k}_{\mathrm{h}} \cos \left(\mathrm{n} \omega_{0} \mathrm{t}\right)+\cos \left(\omega_{0} \mathrm{t}+\theta\right)\right] \\
& \text { where } n=2,3, \ldots, 50
\end{aligned}
$$

where $k_{h}$ is the relative amplitude, either 0.01 or 0.1 in these tests. At reporting times nT, the PMU shall produce a positive sequence measurement of

$$
\mathrm{X}(\mathrm{nT})=\left\{\mathrm{X}_{\mathrm{m}} / \sqrt{ } 2\right\} \angle \theta
$$

\section{5) Discussion}

The proposed theoretical phasor models are the reference phasor value which PMU shall provide the measurement within the IEEE standard compliance. The work listed the initial results of the TVE compliance.

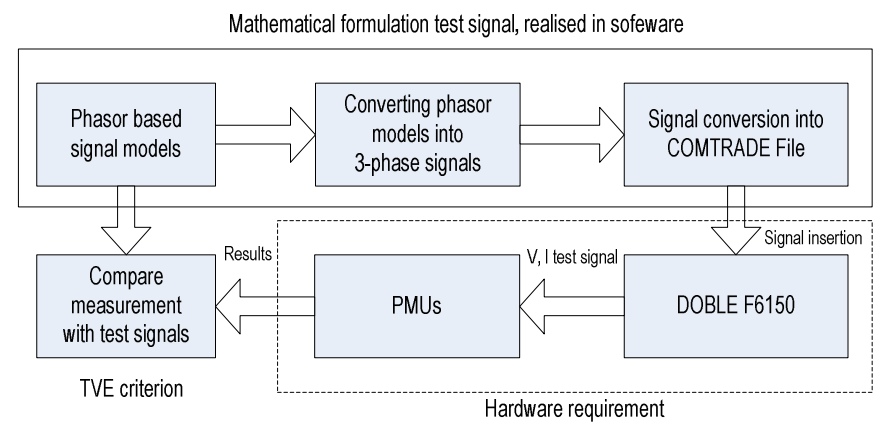

Fig. 2. PMU test procedure

\section{TEST SETUP}

The Centre for Electric Technology (CET), Technical University of Denmark (DTU) has developed a PMU laboratory for PMU research. The PMU can be tested under different conditions via using playback files. The test plans are written in Matlab and then the generated voltage and current signals are converted into a Comtrade file. The signals are transmitted from $\mathrm{PC}$ to a physical synchronized signal generator, here a Doble F6150, to send the test signals to PMUs. The test procedure basically contains a PC, a PMU, and a signal generator. The Doble software, Protest, loads the 'Comtrade' format [9] test file into the F6150 and operates the test. The procedure is illustrated in Fig. 2.

The tests were run on two PMUs from different vendors. The characteristics of the PMU performance are recorded and analyzed. The synchrophasors measured by PMUs are compared with the theoretical phasor proposed above to investigate the compliance with the TVE criterion. Calibration of the phasor values before comparison is required.

In the test, the instrumentation error may come from different sources. The test equipment shall be calibrated before testing. In addition, in the test plans, no test signal is given to the PMU in the few seconds in order to settle the PMU measurement. The measurement from PMU in this period shall be in the vicinity of zero and if not, the offset may result

\begin{tabular}{|c|c|c|c|c|c|}
\hline & Test setup & 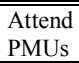 & $\begin{array}{l}\text { Report } \\
\text { Rate }\end{array}$ & $\begin{array}{l}\text { Test } \\
\text { Phase }\end{array}$ & $\begin{array}{l}\text { C37.118 } \\
\text { Compliance }\end{array}$ \\
\hline $\begin{array}{l}\text { Signal } \\
\text { Magnitude }\end{array}$ & $\begin{array}{l}\text { Voltage at } \\
0.1-1.2 \mathrm{pu}\end{array}$ & PMU1 & 50 & $\mathrm{~V}_{\mathrm{a}}$ & $\mathrm{Y}$ \\
\hline \multirow{2}{*}{$\begin{array}{l}\text { Signal } \\
\text { Phase angle }\end{array}$} & \multirow{2}{*}{$\begin{array}{l}\text { Phase angle at } \\
5-360 \mathrm{deg}\end{array}$} & PMU1 & 50 & $\mathrm{~V}_{\mathrm{a}}$ & $\overline{\mathrm{Y}}$ \\
\hline & & PMU2 & 50 & $\mathrm{~V}_{\mathrm{a}}$ & $\mathrm{Y}$ \\
\hline \multirow[t]{2}{*}{$\begin{array}{l}\text { Amplitude } \\
\text { Modulation }\end{array}$} & \multirow{2}{*}{$\begin{array}{l}\text { Modulation } \\
\text { frequency } \\
0.1-5 \mathrm{~Hz}, \max \\
\text { range } 0.1 \mathrm{pu}\end{array}$} & PMU1 & 50 & $\mathrm{~V}_{\mathrm{a}}$ & - \\
\hline & & PMU2 & 50 & $\mathrm{~V}_{\mathrm{a}}$ & - \\
\hline $\begin{array}{l}\text { Phase angle } \\
\text { Modulation }\end{array}$ & $\begin{array}{l}\text { Modulation } \\
\text { frequency } \\
0.1-1.5 \mathrm{~Hz} \text {, } \\
\text { max range } \\
0.26 \mathrm{rad}\end{array}$ & PMU2 & 50 & $\overline{V_{a}}$ & $\begin{array}{l}\mathrm{Y} \\
\end{array}$ \\
\hline \multirow[t]{2}{*}{$\begin{array}{l}\text { Harmonic } \\
\text { Tests }\end{array}$} & \multirow{2}{*}{$\begin{array}{l}\text { Harmonic } \\
\text { frequency } \\
\text { order } \\
2-50\end{array}$} & PMU1 & 50 & $\mathrm{~V}_{\mathrm{a}}$ & $\mathrm{Y}$ \\
\hline & & PMU2 & 50 & $\mathrm{~V}_{\mathrm{a}}$ & $\begin{array}{c}\mathrm{Y} \\
\end{array}$ \\
\hline $\begin{array}{l}\text { Frequency } \\
\text { Ramping }\end{array}$ & $\begin{array}{l}\text { Ramping rate } \\
1 \mathrm{~Hz}, \max \\
\text { range } 20 \mathrm{~Hz}\end{array}$ & PMU2 & 50 & $\mathrm{~V}_{\mathrm{a}}$ & - \\
\hline
\end{tabular}

TABLE I

TEST SETUP AND RESULT SUMMARY

from the test equipment, communication, or measurement. This has to be compensated and jointly coordinated with the test equipment calibration before processing the measurement.

\section{INITIAL RESULTS ON TVE CRITERION COMPLIANCE}

Tests are run on two PMUs from different vendors. The nominal frequency is $50 \mathrm{~Hz}$, with nominal values voltage and current of Doble F6150 at $70 \mathrm{~V} / 5 \mathrm{~A}$, respectively. The test setup and summary are detailed in Tab. I. For all the result figures, the TVE error is the average TVE of phasors measured over a certain time period (dwell) where the parameters of signals are keeping constant. The standard deviation of the TVE at each dwell is also investigated for most of the tests. The analysis is done under the reporting rate $50 \mathrm{~Hz}$. The results are listed in a sequel.

\section{1) Signal magnitude}

The test setup and evaluation results on signal magnitude test are listed in Table I. The PMU1 is involved in the test. Fig. 3-4 illustrate the results regarding the TVE error at different magnitude ranges and reporting rate of PMU1. It is seen that the PMU1 has very accurate magnitude measurement with respect to different input voltage magnitude. Also, the accuracy is higher when the voltage magnitude around $1 \mathrm{pu}$ while becoming lower with the magnitude far from the nominal value. Also, the standard deviation of the TVE error shows the similar trend with the increasing of input voltage magnitude.

\section{2) Signal phase angle}

This test involves both PMU1 and PMU2. The result plots are listed from Fig. 5-8. For Fig. 5-6, it can be seen that the PMU1 has higher phase angle measurement error than the requirement from the standard c37.118. Further investigating the measurement, it is found that there is an angle measurement delay which influences the TVE, see Fig. 9. In practical use, a scaling correction factor on the phase angle measurement is necessary before using the PMU data. To illustrate this, correction factor is added to the measurement before presenting to the comparison. From the TVE shown in 
Fig. 9, it can be seen that the corrected measurement achieves good accuracy with the compliance to the current standard.

In the contrary, PMU2 shows fast, accurate and robust behavior with the different phase angle inputs, as can be seen from Fig. 7-8. Few measurements are not stable at the 360 degree angle input where the test is approaching the end. This yields larger standard deviation than usual conditions.

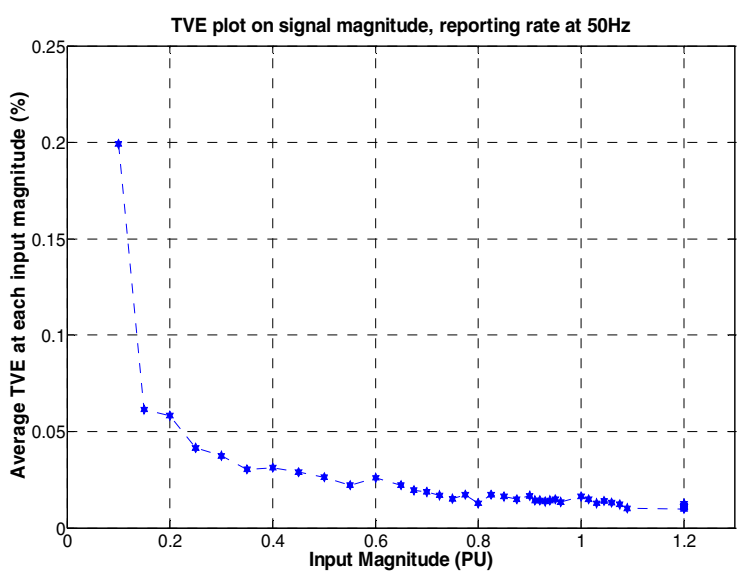

Fig. 3. Average TVE of PMU1 at each input magnitude.

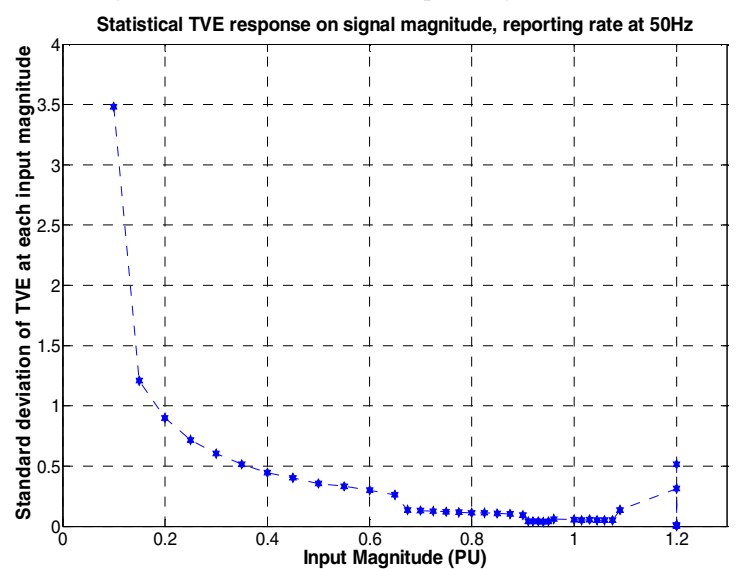

Fig. 4. Standard deviation of PMU1 TVE performance at each input magnitude.

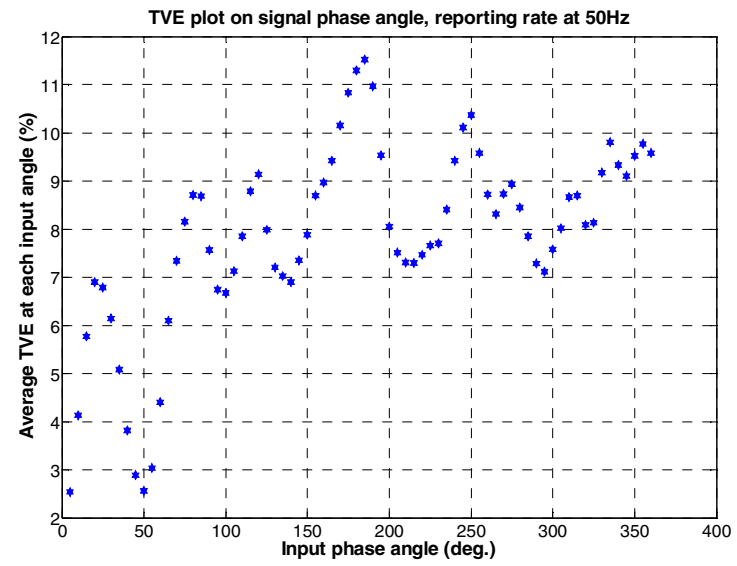

Fig. 5. Average TVE error at each input phase angle of PMU1.

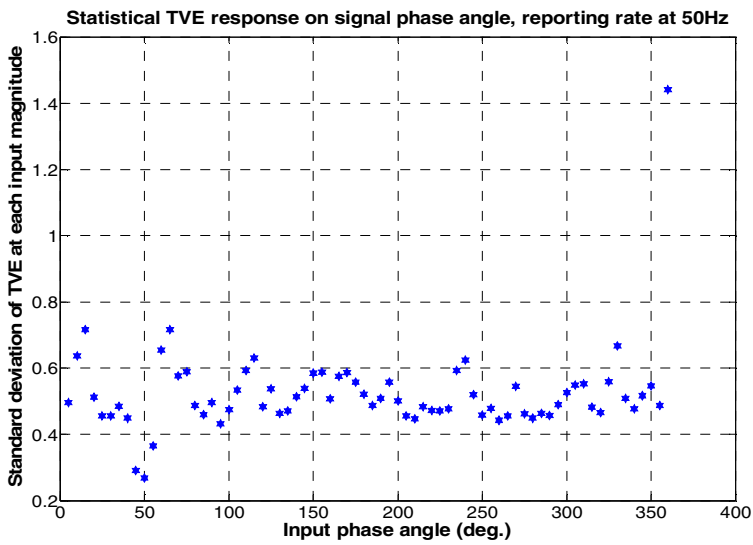

Fig. 6. Standard deviation of PMU1 TVE at each phase angle.

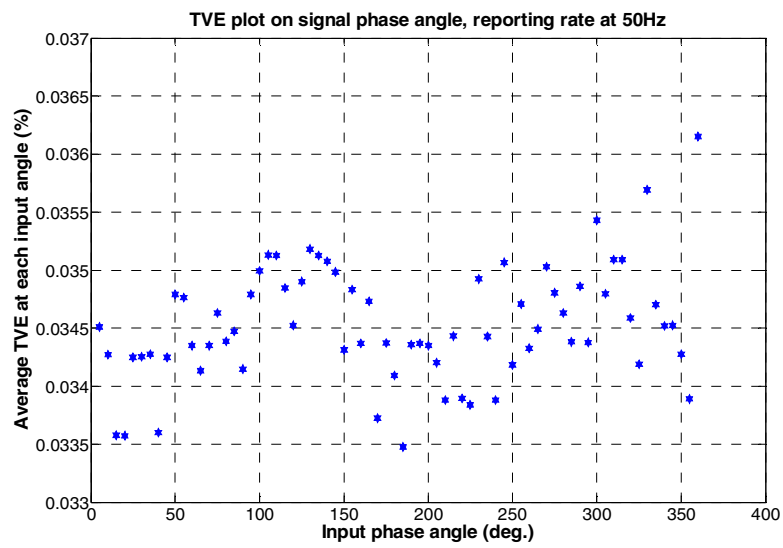

Fig. 7. Average TVE of PMU2 at each input phase angle.

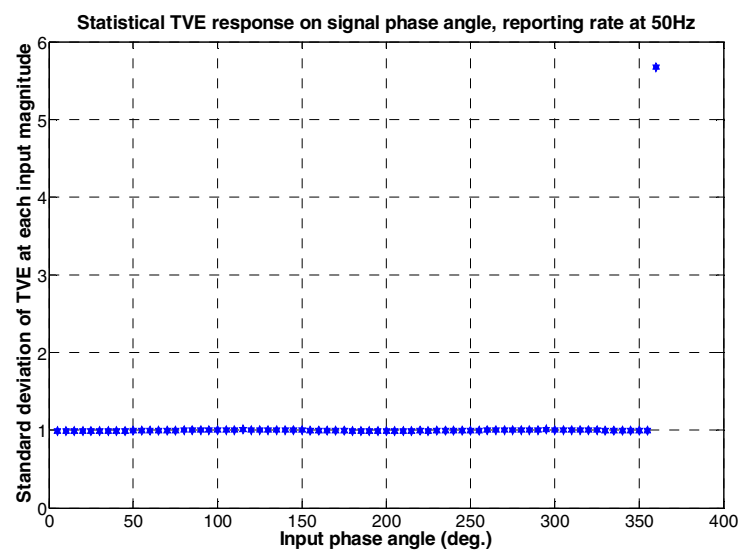

Fig. 8. Standard deviation of PMU2 TVE at each phase angle.

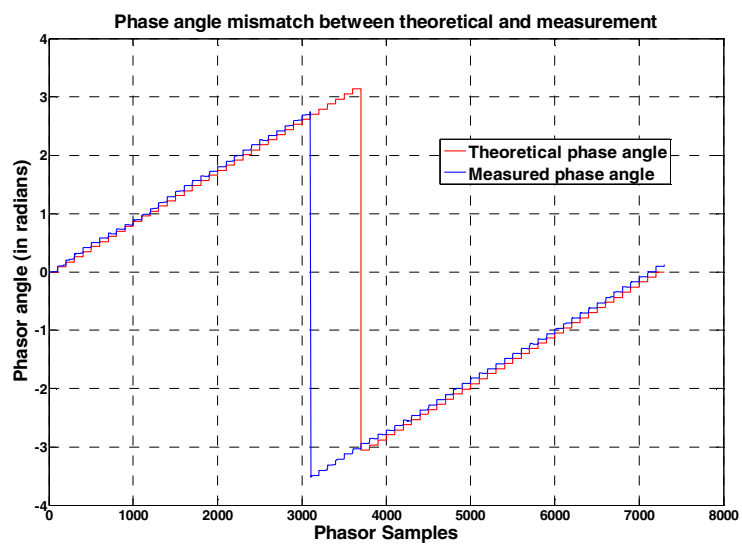

Fig. 9. Comparison between theoretical angle and PMU1 measurement. 


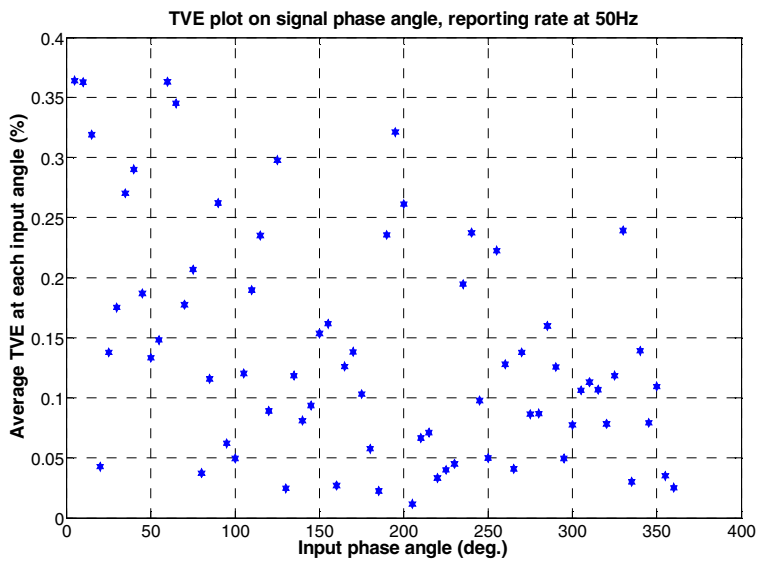

Fig. 10. Average TVE of PMU1 at each input phase angle after delay compensated.

\section{3) Amplitude modulation}

For the amplitude test, the formulation of the theoretical phasor is difficult due to the amplitude of the signal keeps varying throughout the test. An example is given in Appendix I on the modulated amplitude comparing with the fundamental sine wave without the modulation quantity. The modulated signal can be seen as a signal contains both the fundamental and the harmonic frequency components. In this work, the root mean square value is used to represent the theoretical phasor magnitude.

The TVE and the standard deviation of the measurement for two PMUs are illustrated from Fig. 10 - 13. It is found that with the increasing of modulation signal frequency, with the low frequency modulation signal $(<2 \mathrm{~Hz})$, PMU can track the modulated magnitude accurately with the TVE less than $1 \%$. However, with the increasing of modulation frequency, PMU loses the track of the influence signal and the magnitude measurement start to be close to the mean value of the varying signal, which yields higher TVE, as shown in Fig. $14-15$.

It is found that a more generalized theoretical phasor formulation is necessary for modulation tests, especially when the modulation frequency goes higher $(>2 \mathrm{~Hz})$. Also, the It has to be mentioned that the results listed in this paper is the initial efforts from the authors using TVE criterion for PMU testing conforming to the new IEEE standard.

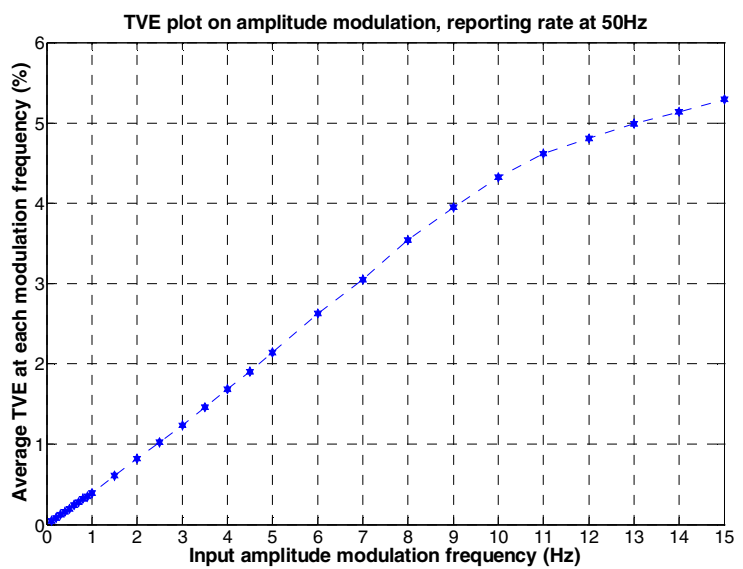

Fig. 11. Average TVE of PMU1 at each amplitude modulation frequency.

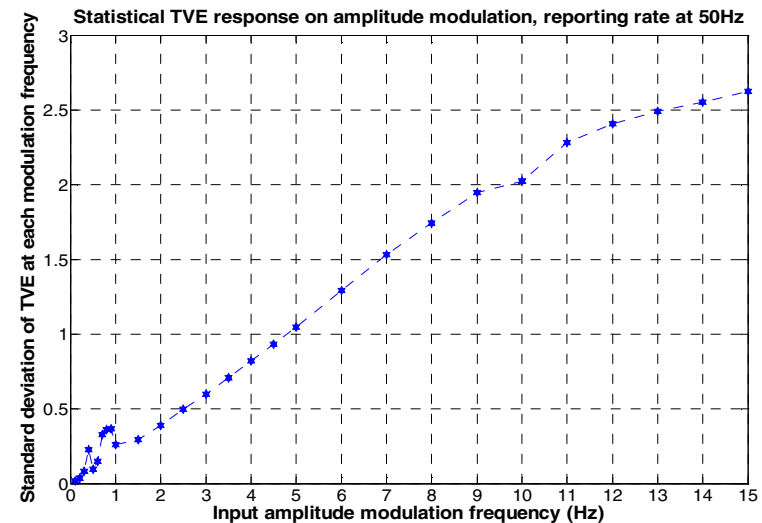

Fig. 12. Standard deviation of PMU1 TVE at each modulation frequency.

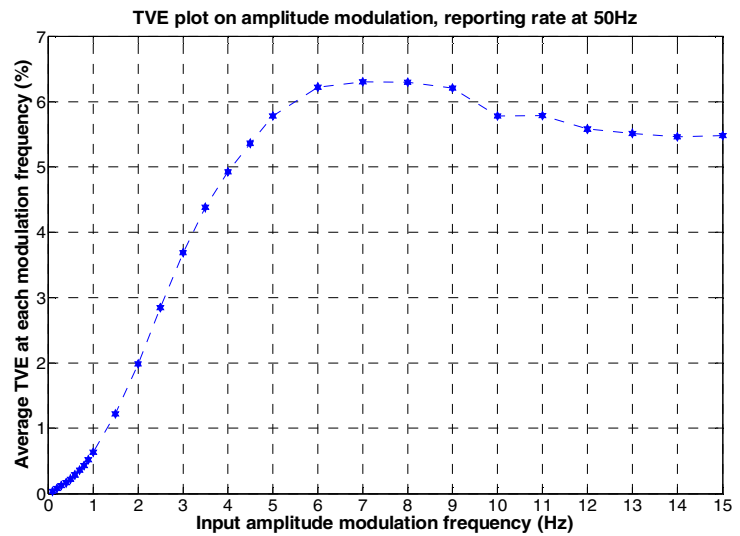

Fig. 13. Average TVE of PMU2 at each input modulation frequency.

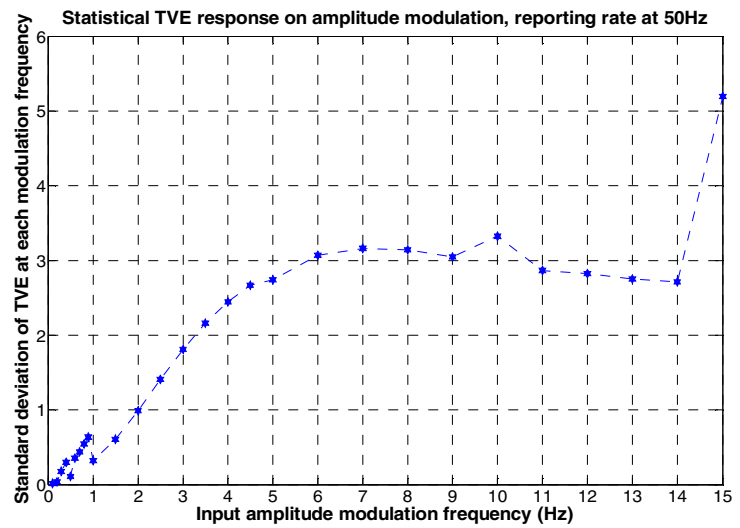

Fig. 14. Standard deviation of PMU2 TVE at each modulation frequency

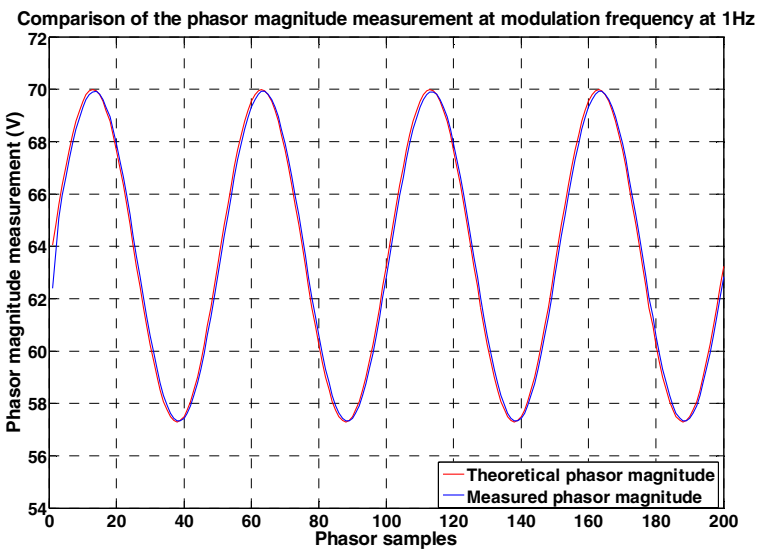

Fig. 15. Comparison between the theoretical and measurement magnitude at modulation frequency $1 \mathrm{~Hz}$. 


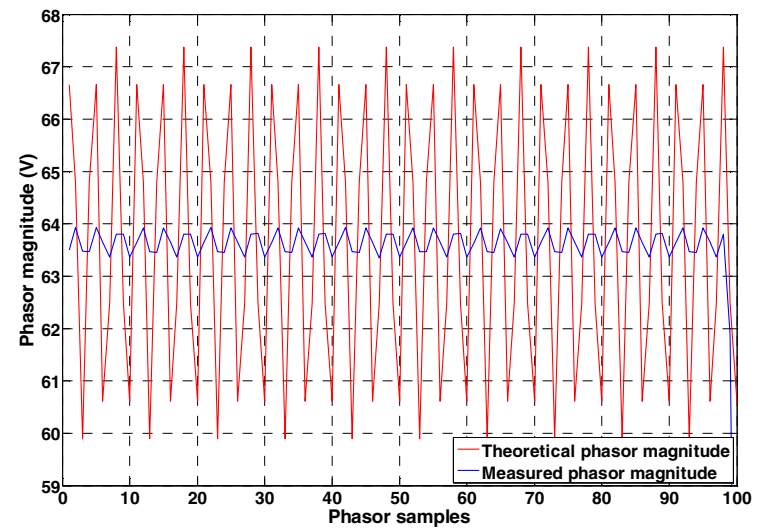

Fig. 16. Comparison between the theoretical and measured magnitude at modulation frequency $15 \mathrm{~Hz}$.

\section{4) Harmonic rejection}

The TVE evaluation on the harmonic test for both PMUs is conforming to the standard and the standard deviations are quite low for both PMUs subject to all the injected harmonics, as can be seen from Fig. 17-20. The injected harmonics at the magnitude $0.1 \mathrm{pu}$ and the frequency order ranges from 2 up to 50 with base frequency $50 \mathrm{~Hz}$.

To generalize the harmonic rejection capability of PMU, tests are also run with off-nominal base frequency. PMU2 is selected and the results are listed from Fig. 21-22. It can be seen that PMU2 shows relatively good harmonic rejection capability at base frequency $49.5 \mathrm{~Hz}$ and $50.5 \mathrm{~Hz}$, respectively.

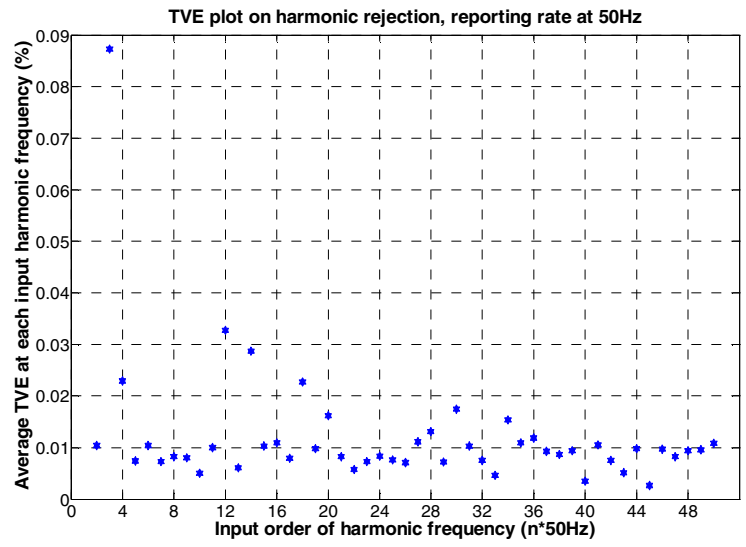

Fig. 17. Average TVE of PMU1 at each harmonic frequency.

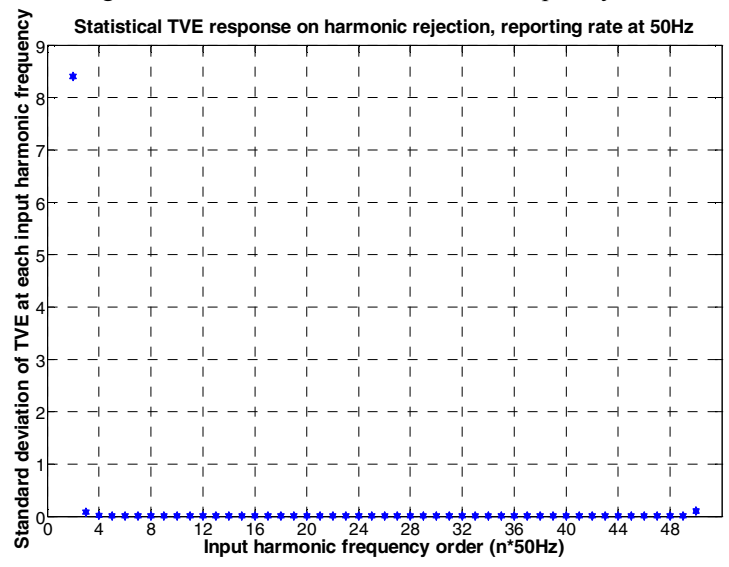

Fig. 18. Standard deviation of PMU1 TVE at each harmonic frequency.

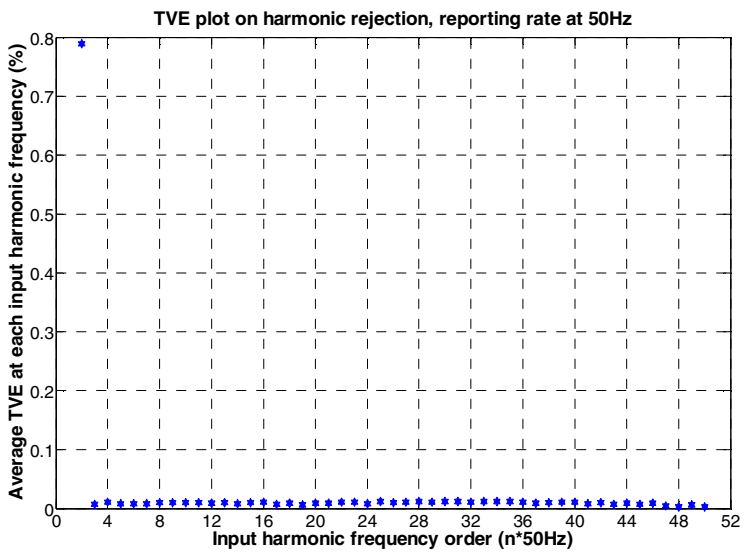

Fig. 19. Average TVE of PMU2 at each input harmonic frequency.

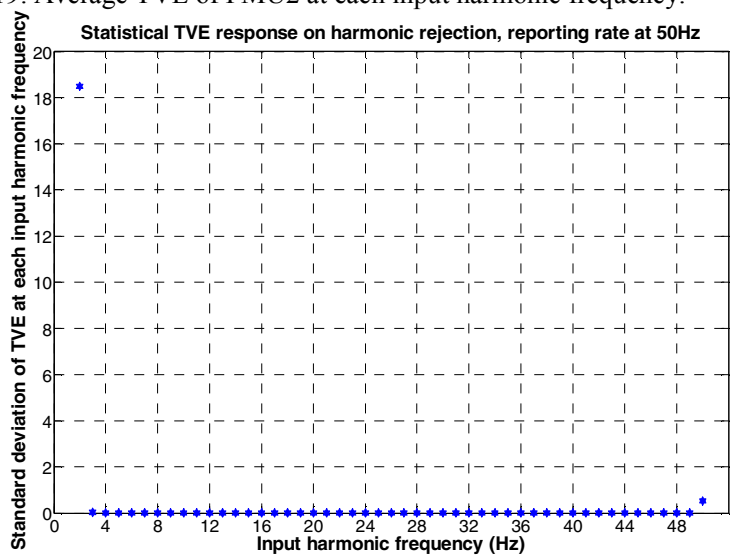

Fig. 20. Standard deviation of PMU2 TVE at each harmonic frequency.

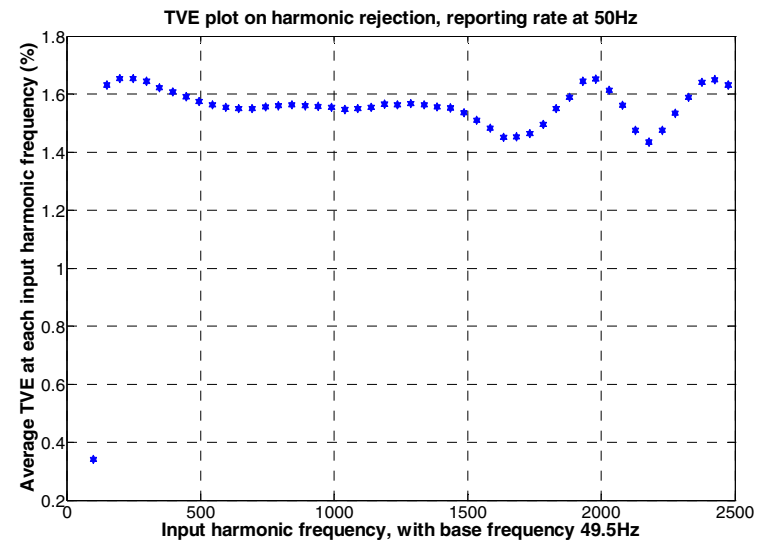

Fig. 21. Average TVE of PMU2 with base frequency $49.5 \mathrm{~Hz}$.

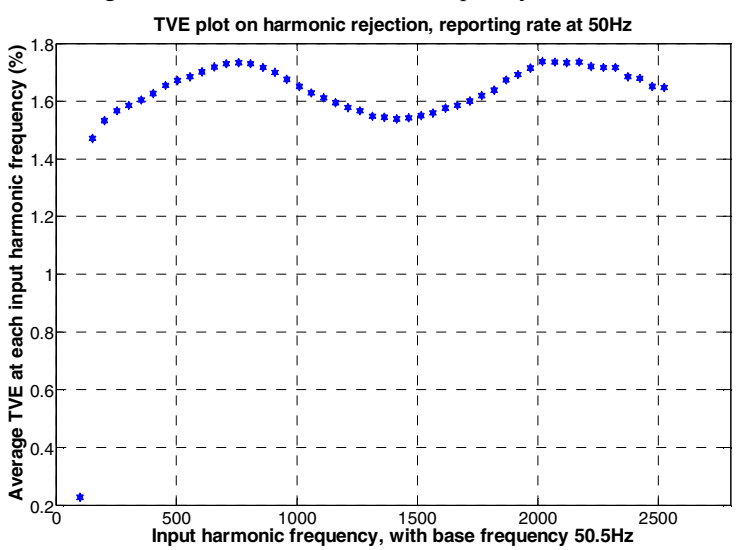

Fig. 22. Average TVE of PMU2 with base frequency $50.5 \mathrm{~Hz}$. 


\section{5) Frequency ramping}

The frequency ramping test is run for the PMU2. The ramping frequency is at rate $1 \mathrm{~Hz}$, and ranges from $-20 \mathrm{~Hz}$ to $20 \mathrm{~Hz}$ off the nominal frequency. As can be seen from the Fig. 23 , the measured frequency is quite accurate and there is nearly no delay during the test. The TVE for this test is under development.

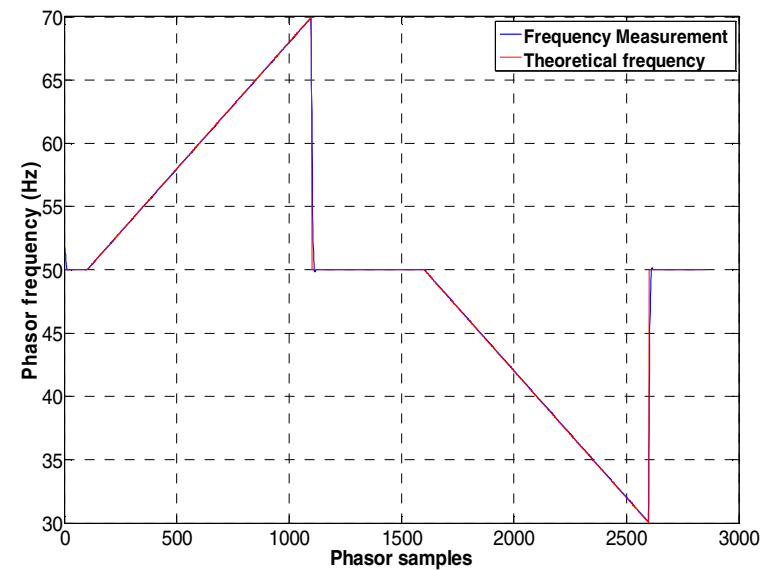

Fig. 23. Comparison of the frequency between the test signal and the measurement.

6) TVE and magnitude and angle analysis

TVE provides a comprehensive accuracy index for both magnitude and angle measurement. It is found that if there are frequency/angle spikes in the measurement, which will drift the angle or frequency measurement from the expected value and hence may yield very high TVE in the results. It can be concluded that TVE provides proportional penalty to the error if one of the signal parameters measurement is far from the theoretical value, specially seen in frequency and angle measurement. The magnitude and angle analyses are still required to find out the reason where the TVE is introduced. For example, for the PMU1 phase scan test, the whole error is introduced from the angle measurement due to the delay, as shown in Fig. 9; while for PMU1 amplitude modulation test, the error only results from the magnitude measurement (Fig. $11-12)$.

\section{CONCLUSION}

The paper lists the initial results using TVE to investigate the PMU performance conforming to the IEEE standard. The results are compared between the theoretical phasor value and the measurement. Beside this, the standard deviation of the TVE within a certain time interval (dwell) is investigated for PMU performance evaluation. This index provides the robustness of PMU measurement. It is found that the TVE error is mostly influenced by the frequency and angle measurement since the measurement error can be aggregated over the time which will cause proportional error from TVE evaluation. Also, it is felt that a more generalized and accurate description of phasor is necessary for amplitude modulation tests. Also, it is realized that there would be some incompatibility between the tests which presents difficulties for error evaluation, such as amplitude modulation test and harmonic test. The authors will continue this effort to further investigate the PMU performance under the TVE criterion.

\section{APPENDIX}

An example of amplitude modulation test is demonstrated below.

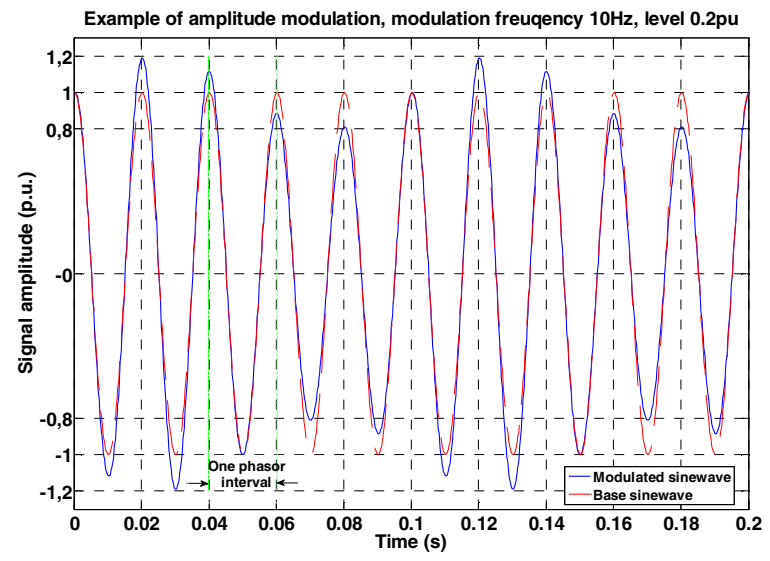

Fig. 24. Amplitude modulation example.

\section{REFERENCES}

[1] "IEEE Standard for Synchrophasors for Power Systems," IEEE Std C37.118-2005 (Revision of IEEE Std 1344-1995), 2006.

[2] K. E. Martin and J. Stenbakken, "PMU System Testing and Calibration Guide," NASP Performance \& Standards Task Team (PSTT), 2007.

[3] K. E. Martin, T. Faris, and J. Hauer, "Standardized Testing of Phasor Measurement Units," in Fault and Disturbance Analysis Conference Georgia Tech, Atlanta, GA, 2006.

[4] H. Zhenyu, J. F. Hauer, and K. E. Martin, "Evaluation of PMU Dynamic Performance in Both Lab Environments and under Field Operating Conditions," in IEEE Power Engineering Society General Meeting, 2007.

[5] J. Depablos, V. Centeno, A. G. Phadke, and M. Ingram, "Comparative Testing of Synchronized Phasor Measurement Units," in IEEE Power Engineering Society General Meeting, vol.1, pp. 948-954, 2004.

[6] J. Ren, M. Kezunovic, and G. Stenbakken, "Dynamic Characterization of PMUs Using Step Signals," in IEEE Power \& Energy Society General Meeting, 2009.

[7] G. Stenbakken and Z. Ming, "Dynamic Phasor Measurement Unit Test System," in IEEE Power Engineering Society General Meeting, 2007.

[8] F. Dawei, V. Centeno, and Z. Hengxu, "Aspects on Relative Phase Angle Measurement," in IEEE Power Engineering Society General Meeting, 2007.

[9] "IEEE Standard Common Format for Transient Data Exchange (COMTRADE) for Power Systems," IEEE Std C37.111 - 1999, 1999. 